\title{
28 Research Square \\ Comprehensive Analysis of Key Genes and Regulatory Elements in Ewing Sarcoma With Prognostic Values
}

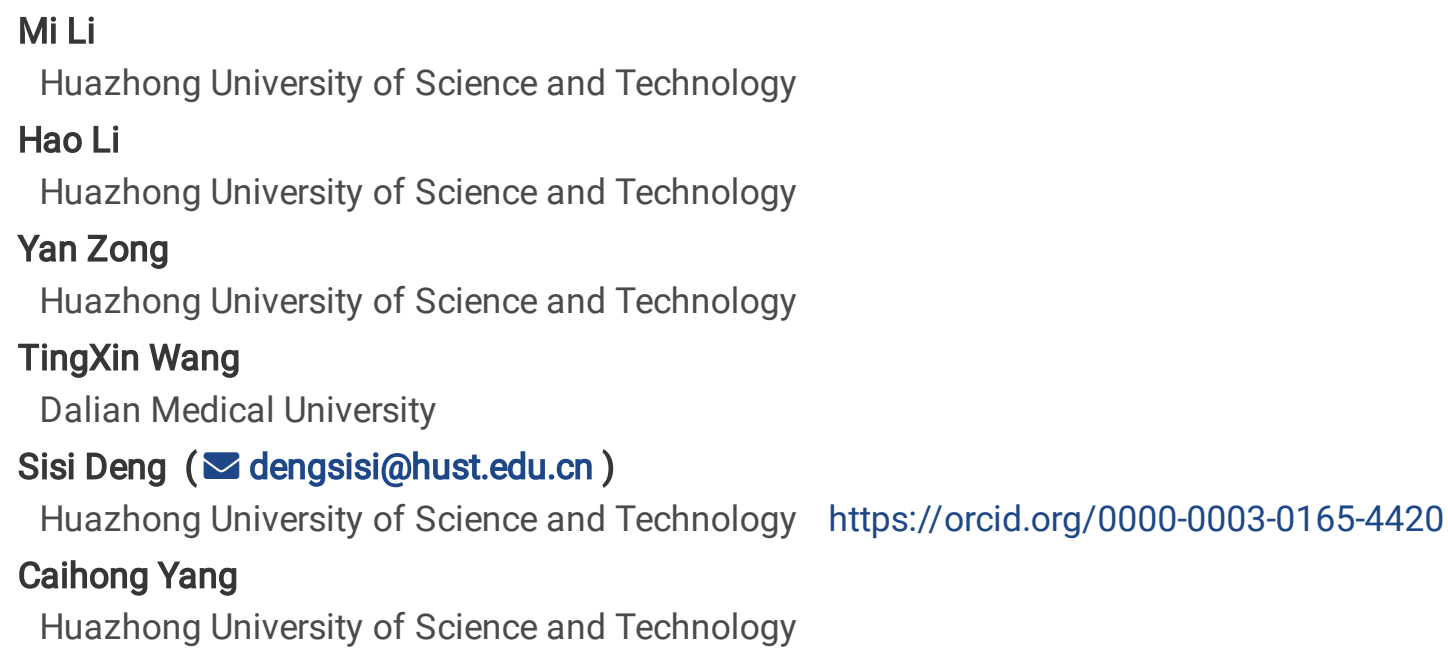

Mi Li

Huazhong University of Science and Technology

Hao Li

Huazhong University of Science and Technology

Yan Zong

Huazhong University of Science and Technology

TingXin Wang

Dalian Medical University

Sisi Deng ( $\nabla$ dengsisi@hust.edu.cn )

Huazhong University of Science and Technology https://orcid.org/0000-0003-0165-4420

Caihong Yang

Huazhong University of Science and Technology

\section{Research article}

Keywords: Ewing sarcoma, comprehensive analysis, protein-protein interaction network, differentially expressed genes, regulatory elements

Posted Date: March 13th, 2021

DOI: https://doi.org/10.21203/rs.3.rs-307247/v1

License: (c) (i) This work is licensed under a Creative Commons Attribution 4.0 International License. Read Full License 


\section{Abstract}

Background: Ewing sarcoma (ES) is one of the most common types of round cell mesenchymal neoplasms related to children and young adults. It is characterized by chromosomal translocations. However, that does not completely explain the ES proliferation and development.

Methods: Several public data series (GSE45544, GSE68591, and GSE68776) were used to identify differentially expressed genes (DEGs) between ES and normal tissue. Furthermore, functional enrichment analysis and protein-protein interaction network of DEGs were performed. The regulatory network of DEGs and hub genes, survival analysis of hub genes was visualized. In addition, functional predictions of the candidate gene were analyzed.

Results: A total of 142 DEGs 10 hub genes were identified. While out of them, only one candidate gene FGF7 was found to be suitable as a candidate gene.

Conclusions: In conclusion, the DEGs, hub genes, and their regulatory molecules screened out in this research could contribute to comprehend the mechanisms in ES and provide potential research molecular for further study.

\section{Background}

Ewing sarcoma (ES) is one of the most common types of round cell mesenchymal neoplasms. The prevalence of ES is most often related to children and young adults[1]. Molecularly, ES is characterized by repeated chromosomal translocations, resulting in a framework fusion protein consisting of the amino terminus of the Ewing sarcoma protein (EWS) linked to the carboxy terminus of different transcription factors. In most of the cases, the translocation is a fusion of the Ewing sarcoma breakpoint region 1 (EWSR1) gene on chromosome 22 with the Friend Leukemia Virus Integration Site 1 (FLI1) gene on chromosome 11[2,3]. This aberrant translocation causes the chimeric oncogene EWS-FLI1 which could promote ES pathogenesis[4]. Meanwhile, the clinical presentation of ES still varies from patient to patient. Although the treatment of ES has made great progress through unremitting efforts, there are still some patients who do not respond well to treatment. However, the EWS-FLI1 molecule alone does not completely solve this problem. The major challenges in terms of novel molecular players could be involved in ES proliferation and development.

In recent years, with the development of sequencing technology, enormous amounts of data of tumors had been generated. Bioinformatics analysis of these data can reveal a better understanding of the underlying mechanisms of tumor development. Nowadays, numerous researches have been published on many different cancer types. Similarly, ES is no exception, some key genes involved in metastasis and development[5-8]. However, these studies contain one or two datasets. Integrating more datasets is likely to yield more valuable findings.

In our study, several microarray datasets from the Gene Expression Omnibus (GEO) database including ES and normal tissues were analyzed to obtained differentially expressed genes (DEGs). Subsequently, functional and pathway enrichment analyses of the DEGs were used to reveal the underlying mechanisms. Besides, a protein-protein interaction (PPI) network was constructed to screen out hub genes in the DEGs. Meanwhile, we constructed regulatory networks of the DEGs and the hub genes. Furthermore, the immune infiltration analysis, DNA methylation analysis, isomer expression analysis, and the survival analysis of the hub genes were carried out to select one candidate gene and to predict the possible function of the candidate gene.

\section{Methods}

\section{Analysis of gene expression profiles to identify the DEGs.}

Three gene expression datasets GSE45544[9], GSE68591[10], and GSE68776[11] containing ES and normal tissue data, as available datasets, were deposited in the GEO (http://www.ncbi.nlm.nih.gov/geo)[12]. The GSE45544 dataset contained 6 
ES patient samples and 22 normal tissues samples. The GSE33006 contained 22 ES cell lines and 5 normal human cells. The GSE41804 contained 32 ES patient samples and 33 normal tissue samples. Normal bone marrow was chosen as the contact normal tissue group to the ES. The DEGs between the ES group and the corresponding normal tissue group were analyzed using the R language (version 4.0.2) with the Limma package. The $p$-value $<0.01$ and absolute value of logFC (fold change) $>1$ were considered statistically significant.

\section{Dimensionality Reduction of the DEGs}

In addition, the 3D-PCA dimensionality reduction was performed on samples from tumor sarcoma tissue, normal tissue, and skeletal muscle tissue using the online database GEPIA2 (http://gepia2.cancer-pku.cn/index.html)[13]. The data was based on their expression of a group of genes.

\section{GO functional analysis and pathway enrichment of DEGs}

Gene Ontology (GO)[14] and Kyoto Encyclopedia of Genes and Genomes (KEGG) [15]analyses of DEGs were performed by WebGestalt (WEB-based Gene SeT AnaLysis Toolkit, http://www.webgestalt.org)[16], which is a continuously updated useful functional enrichment analysis web tool. Over-Representation Analysis (ORA) was selected as the analyzed method. The GO functional enrichment was performed in the biological process no Redundant (BP), cellular component no Redundant (CC), molecular function no Redundant (MF), and the pathway analysis was performed in the KEGG pathway. The $p$-value $<0.05$ was considered to indicate statistical significance.

\section{Construction of the PPI network to select hub genes}

The STRING database (online Search Tool for the Retrieval of Interacting Genes, http://string-db.org, RRID: SCR_005223) [17] was used to predict a PPI network of DEGs. The selecting parameter was that the interaction scores greater than 0.4 . Furthermore, the network was visualized by Cytoscape software (version 3.8.0) [18]. Then, MCODE (Molecular Complex Detection,) [19], a plug-in of Cytoscape, was open to select hub genes, with the following criteria: MCODE score $>5.5$, degree cut-off=2, score cut-off=0.2, max depth=100, and k-score=2.

\section{Regulatory network of the hub genes}

To analyze the miRNA-gene and TF-gene networks among DEGs and hub genes, the database NetworkAnalyst (https://www.networkanalyst.ca/NetworkAnalyst/home.xhtml)[20] was applied to use. NetworkAnalyst is a powerful webbased 3D visual analytics platform for comprehensive profiling, meta-analysis, and systems-level interpretation among genes, proteins, miRNAs, transcription factors (TF), and metabolites. In this study, we choose miRTarBase database for building gene-miRNA interactions and the ENCODE database for TF-gene interactions. Besides that, to analyze TF-IncRNA interactions. All the networks above were visualized by Cytoscape software (version 3.8.0)[18].

\section{Immune infiltration analysis of the hub genes}

Tumor IMmune Estimation Resource (TIMER, https://cistrome.shinyapps.io/timer/)[21] is a comprehensive web server for calculating a systematic analysis of immune infiltrates based on the microarray expression values across diverse cancer types. The immune infiltration estimation of the hub genes was performed in SARC dataset by TIMER. The scatterplots of the hub genes were generated to show the purity and different immune cells with partial correlation coefficient and statistical $p$-value.

\section{DNA methylation analysis and Isomer expression analysis of the hub genes}

The level of DNA methylation in the promoter region of the hub genes was obtained from the UALCAN (http://ualcan.path.uab.edu/index.html)[22]. While the analysis of the expression level of the isomers of the hub genes was also obtained by GEPIA2[13]. 


\section{Survival analysis of the hub genes}

PROGgeneV2 (http://genomics.jefferson.edu/proggene)[23] is a comprehensive web tool that can be used to indicate the prognostic significance of genes with publicly available data. All the hub genes were performed separately with the cancer type chosen in the sarcoma dataset. The overall survival plots were created based on the cohort divided at the median expression of the given input gene. The hub genes that had $p$-values $<0.05$ were considered as candidate genes and taken further analyzed.

\section{Prediction of functions of the candidate genes}

The database GeneMANIA (http://www.genemania.org)[24] was used to construct the functional association network among the candidate genes and their interactive genes. The statistical options were as follows: $\max$ resultant genes $=20$, max resultant attributes $=10$. Subsequently, the expression of candidate genes in normal and corresponding malignant tissues was displayed by the Anatomic Viewer of the online SAGE database (http://www.ncbi.nlm.nih.gov/SAGE)[25]. Furthermore, the heatmaps of positively and negatively correlated significant genes of the candidate genes were illustrated by the LinkedOmics (http://www.linkedomics.org/)[26]

The parameter selection of all these tools above is based on the developers' references to select the most appropriate parameters.

\section{Results}

\section{Identification and PCA analysis of the DEGs.}

After standardization of the microarray results, DEGs (5,744 in GSE68591, 1,859 in GSE45544 and 2,066 in GSE68776) were identified. The overlap among the 3 datasets contained 142 genes as shown in Fig. 1A. While the PCA dimensionality reduction showed a good distinction between the expression of genes among the tumor sarcoma tissue, normal tissue, and skeletal muscle tissue (Fig. 1B).

\section{GO functional analysis and pathway enrichment of DEGs}

The biological classification, functional and pathway enrichment analyses of DEGs are shown in Fig. 2 (details are shown in Table 1). In biological processes (BP) ontology, DEGs were significantly enriched in positive regulation of cell motility, leukocyte migration, and neutrophil mediated immunity (Fig. 2A). In molecular function (MF) ontology, DEGs were mainly enriched in growth factor binding, extracellular matrix structural constituent, and transmembrane receptor protein kinase activity (Fig. 2B). In cell component (CC) ontology, DEGs were mainly enriched in the extracellular matrix, secretory granule membrane, and specific granule (Fig. 2C). Besides that, KEGG pathway analysis revealed that the terms were related to the Rap1 signaling pathway, Ras signaling pathway, and Glycine, serine, and threonine metabolism (Fig. 2D).

\section{Construction of the PPI network to select hub genes}

The PPI network of the DEGs was constructed by Cytoscape as shown in Fig. 1C, while the most significant module with 10 nodes and 17 edges as shown in Fig. 1D. These 10 genes were identified as hub genes and the detailed information of hub genes is provided in Table 2. The hub genes may be an important regulatory network in the development of ES.

\section{Regulatory network of the hub genes}

The DEG-miRNA (Fig. 3A), TF-DEG (Fig. 3B), hub gene-miRNA (Fig. 3C), and TF-hub gene (Fig. 4D) interaction regulatory networks were constructed and visualized by Cytoscape. The top 5 miRNAs that significantly regulated the DEGs were hsamir-124-3p, hsa-mir-335-5p, hsa-mir-16-5p, hsa-mir-26b-5p, and hsa-mir-1-3p While the top 5 TFs significantly interacted with the DEGs were TFDP1, ZNF580, ZBTB11, PHF8, and KDM5B. Furthermore, the top 5 miRNAs that significantly regulated the 
hub genes were hsa-mir-218-5p, hsa-mir-122-5p, hsa-mir-335-5p, hsa-mir-128-3p, and hsa-mir-124-3p. While the top 10 TFs that significantly interacted with the hub genes were ZNF580, MXD3, SAP30, KDM5B, and PHF8. The topological properties of the miRNAs and TFs are displayed in Table 3 and Table 4. These DEG-miRNA, TF-DEG, hub gene-miRNA and TF-hub gene networks provide evidence for further experimental verification.

\section{Immune infiltration analysis of the hub genes}

The expression levels of CTSB, CTSD, HMOX1, BCL2L1, CD68, TEK, IL1R1, and VEGFC were negatively associated with tumor purity while FGF7 and PTGS2 were positively associated with tumor purity (Fig. 4). This result indicated that most hub genes are probably expressed in the microenvironment, while FGF7 and PTGS2 are probably expressed in the tumor cells.

\section{DNA methylation analysis and Isomer expression analysis of the hub genes}

Furthermore, the relationship between DNA methylation level in the promoter region of the hub genes and the occurrence of SARC was explored. It was found that only the DNA methylation levels of CTSB in SARC were significantly lower than those in corresponding normal tissues, while there was no significant difference in other genes (Fig. 5). Meanwhile, the expression levels of isomers of the hub genes were also analyzed. For BCL2L1, BCL2L1-004 are highly expressed in SARC. For CD68, CD68-001 and CD68-002 are highly expressed in SARC. For CTSB, CTSB-006 and CTSB-001 are highly expressed. For CTSD, CTSD-001 and CTSD-006 are highly expressed. For FGF7, FGF7-001 are highly expressed. For HMOX1, HMOX1-001 are highly expressed. For PTGS2, PTGS2-001 are highly expressed. For TEK, TEK-002 is highly expressed. For IL1R1, IL1R1-005 and IL1R1-001 are highly expressed. For VEGFC, VEGFC-001 is highly expressed (Fig. 6).

\section{Survival analysis of the hub genes}

The overall survival plots of hub genes could be obtained as shown in Fig. 7. Unfortunately, most of them, namely CTSB, CTSD, HMOX1, BCL2L1, CD68, TEK, IL1R1, PTGS2, and VEGFC, had no statistically significant difference in the survival curve. While only FGF7 had a p-value < 0.05 . High expression of FGF7 had a better overall survival (Fig. 7).

Together with all the results above, FGF7 is one of the hub genes which could probably be expressed in the tumor cells and its expression had a relationship with the prognosis of ES patients. Therefore, FGF7 was considered as a candidate gene for further analyses.

\section{Prediction of functions of the candidate genes}

A functional network of FGF7 and interactive association genes was constructed by GeneMANIA. The function of this gene set was mainly enriched to fibroblast growth factor receptor signaling pathway, mesenchymal cell proliferation, and renal system development (Fig. 8A). Besides that, the expression profiles of the FGF7 in human tissue are displayed. As shown, FGF71 mRNA in thyroid, lung, and colon normal tissues displayed higher levels than in the matched cancer tissues (Fig. 8B). Subsequently, the gene expression correlation heatmaps indicated that ATP8B4, IL33, A2M, NPR1, and PPAP2A were the most positively correlated significant genes of FGF7 (Fig. 8C), and WNT7B, PRR7, NOTUM, ETV4, and RPSAP52 were the most negatively correlated significant genes of FGF7 (Fig. 8D). All these findings predict the function of FGF7 and can be helpful for further research.

\section{Discussion}

The genetics of ES is relatively simple and are driven by chromosomal translocations leading to fusion oncogenes [27]. The oncogene EWS-FLI1 plays as an aberrant transcription factor which is enhanced by its interaction with several molecular partners. The current study found that the RNA helicase A (RHA), which interacted with EWS-FLI1, would lead to cancer 
progression and drug resistance [28]. Besides that, RHA also enhances EWS-FLI1-mediated transcription and promotes migration and proliferation of ES cells[29].

In our present study, several microarray datasets analyses were used to obtain DEGs and hub genes together with their regulatory elements from ES contrast to normal tissue. Altogether, 142 DEGs, 10 hub genes, and 1 candidate gene FGF7 were identified. Subsequently, further analyses of the hub genes were used to explore some other interactions. Previous studies have reported that some key molecules could strongly induce the motility and invasion of ES cells[30]. Moreover, studies have revealed that different constituents of the extracellular matrix may be held responsible for its effects on different parameters of ES proliferation[31]. Meanwhile, IGF-1R/RAS/Rac1 signaling played a role in the hyperstimulation of macro-pinocytosis and selective death of EW cells[32]. In summary, all these studies are consistent with the results obtained in our studies.

Consistently, 10 hub genes were screened out from the PPI network of DEGs. Some of them have been stated involved in the tumorigenesis and progression of ES. A previous study revealed that BCL2 interacted with BCLXL to escape PARP inhibitor toxicity in ES[33]. The density of CD68-positive Tumor-associated macrophages was found in ES tissue samples and statistically correlated with clinical parameters [34]. Meanwhile, TEK and VEGFC were reported their expression was upregulated in ES which may allow the development of sarcoma subtype-targeted therapeutics[35, 36]. Interestingly, Celecoxib, a PTGS2 (also known as cyclooxygenase-2, COX-2) inhibitor, could significantly inhibit the invasion and migration of ES cells[37, 38].

In contrast, a search of published literature revealed that the other hub genes have been associated with tumors. It is previously described that inhibitors and small interfering RNA (siRNA) targeting CTSB could inhibit Kaposi's sarcoma proliferation which was crucial for the transformation of endothelial cells[39]. The mRNA and protein expression of HMOX1 were up-regulated in and treatment with the HMOX1 inhibitor could reduce the proliferation of Kaposi's sarcoma[40]. Additionally, when infused $\mathrm{\delta} \delta \mathrm{T}$ cells lacked IL-1R1, their anticancer immune responses were lost[41].

Further survival analysis revealed FGF7 as a candidate gene because of its significantly statistical function. Notably, there was no report on FGF7 in ES, while there had been some studies in sarcoma. In leiomyosarcoma, the SK-LMS-1 cells only responded to exogenous FGF7 but did not respond to VEGF[42]. In chondrosarcoma, aberrant splicing of fibroblast growth factor receptor was able to bind FGF7, leading to loss of ligand-binding specificity[43]. In contrast, there was another research reported that FGF7 was a preferentially used growth factor in cancer, which was based on the special type receptor in carcinoma cells but not on alternative splicing in sarcoma cells[44].

In this work, a disadvantage is that the information on DEGs, hub genes and their regulatory elements involved in ES are analyzed via bioinformatics. However, the relationship of these molecules has not been confirmed. Furthermore, in vivo and in vitro experiments and analyses are required to test the biological functions of the DEGs and hub genes.

\section{Conclusions}

In conclusion, we identified 142 DEGs, 10 hub genes, and 1 candidate gene FGF7. All of these genes are involved in the development of ES. And the hub genes, especially the candidate gene FGF7, may contribute to being the potential targets for future research and the biomarkers for Ewing sarcoma.

\section{List Of Abbreviations}

DEGs: differentially expressed genes

PPI: protein-protein interaction

GO: Gene Ontology

Page 6/21 
KEGG: Kyoto Encyclopedia of Genes and Genomes

GEO: Gene Expression Omnibus

STRING: Search Tool for the Retrieval of Interacting Genes

\section{Declarations}

Acknowledgments: Not applicable.

Authors' contributions: ML analyzed the data, $\mathrm{HL}$ and $\mathrm{YZ}$ provided the help of the R language. TW suggested online tools. $\mathrm{SD}$ and $\mathrm{CY}$ designed the project. $\mathrm{CY}$ selected the analyzed results and wrote the paper. All authors read and approved the final manuscript.

Competing interests: The authors declare that the research was conducted in the absence of any commercial or financial relationships that could be construed as a potential conflict of interest.

Ethics approval and consent to participate: Not applicable.

Availability of data and materials: The data that support the findings of this study were generated at GSE45544, GSE68591, and GSE68776 in GEO. Derived data supporting the findings of this study are available from the corresponding author on reasonable request.

Funding: Not applicable.

\section{References}

1. Balamuth NJ, Womer RB: Ewing's sarcoma. Lancet Oncol 2010, 11(2):184-192.

2. Toomey EC, Schiffman JD, Lessnick SL: Recent advances in the molecular pathogenesis of Ewing's sarcoma. Oncogene 2010, 29(32):4504-4516.

3. Delattre O, Zucman J, Plougastel B, Desmaze C, Melot T, Peter M, Kovar H, Joubert I, de Jong P, Rouleau G et al: Gene fusion with an ETS DNA-binding domain caused by chromosome translocation in human tumours. Nature 1992, 359(6391):162-165.

4. Cidre-Aranaz F, Alonso J: EWS/FLI1 Target Genes and Therapeutic Opportunities in Ewing Sarcoma. Front Onco/2015, 5:162.

5. Zhang J, Zhang Y, Li Z, Wu H, Xun J, Feng H: Bioinformatics analysis of Ewing's sarcoma: Seeking key candidate genes and pathways. Oncol Lett 2019, 18(6):6008-6016.

6. Li G, Zhang P, Zhang W, Lei Z, He J, Meng J, Di T, Yan W: Identification of key genes and pathways in Ewing's sarcoma patients associated with metastasis and poor prognosis. OncoTargets and therapy 2019, 12:4153-4165.

7. Yan C, Wang Y, Wang Q, Feng X, Wang L, Bu Z, Lu B, Jiang J: Identification of key genes and pathways in Ewing's sarcoma using bioinformatics analysis. Journal of BUON : official journal of the Balkan Union of Oncology 2018, 23(5):1472-1480.

8. Wang B, Li J, Li X, Ou Y: Identifying prognosis and metastasis-associated genes associated with Ewing sarcoma by weighted gene co-expression network analysis. Oncol Lett 2019, 18(4):3527-3536.

9. Agelopoulos K, Richter GH, Schmidt E, Dirksen U, von Heyking K, Moser B, Klein HU, Kontny U, Dugas M, Poos K et al: Deep Sequencing in Conjunction with Expression and Functional Analyses Reveals Activation of FGFR1 in Ewing Sarcoma. Clinical cancer research : an official journal of the American Association for Cancer Research 2015, 21(21):4935-4946. 
10. Teicher BA, Polley E, Kunkel M, Evans D, Silvers T, Delosh R, Laudeman J, Ogle C, Reinhart R, Selby M et al: Sarcoma Cell Line Screen of Oncology Drugs and Investigational Agents Identifies Patterns Associated with Gene and microRNA Expression. Molecular cancer therapeutics 2015, 14(11):2452-2462.

11. Svoboda LK, Harris A, Bailey NJ, Schwentner R, Tomazou E, von Levetzow C, Magnuson B, Ljungman M, Kovar H, Lawlor ER: Overexpression of HOX genes is prevalent in Ewing sarcoma and is associated with altered epigenetic regulation of developmental transcription programs. Epigenetics 2014, 9(12):1613-1625.

12. Clough E, Barrett T: The Gene Expression Omnibus Database. Methods in molecular biology (Clifton, NJ) 2016, 1418:93-110.

13. Tang Z, Li C, Kang B, Gao G, Li C, Zhang Z: GEPIA: a web server for cancer and normal gene expression profiling and interactive analyses. Nucleic acids research 2017, 45(W1):W98-w102.

14. Consortium TGO: The Gene Ontology project in 2008. Nucleic acids research 2008, 36(Database issue):D440-444.

15. Kanehisa M, Goto S: KEGG: kyoto encyclopedia of genes and genomes. Nucleic acids research 2000, 28(1):27-30.

16. Liao Y, Wang J, Jaehnig EJ, Shi Z, Zhang B: WebGestalt 2019: gene set analysis toolkit with revamped Uls and APIs. Nucleic acids research 2019, 47(W1):W199-w205.

17. Szklarczyk D, Morris JH, Cook H, Kuhn M, Wyder S, Simonovic M, Santos A, Doncheva NT, Roth A, Bork P et al: The STRING database in 2017: quality-controlled protein-protein association networks, made broadly accessible. Nucleic acids research 2017, 45(D1):D362-d368.

18. Shannon P, Markiel A, Ozier O, Baliga NS, Wang JT, Ramage D, Amin N, Schwikowski B, Ideker T: Cytoscape: a software environment for integrated models of biomolecular interaction networks. Genome research 2003, 13(11):2498-2504.

19. Bandettini WP, Kellman P, Mancini C, Booker OJ, Vasu S, Leung SW, Wilson JR, Shanbhag SM, Chen MY, Arai AE: MultiContrast Delayed Enhancement (MCODE) improves detection of subendocardial myocardial infarction by late gadolinium enhancement cardiovascular magnetic resonance: a clinical validation study. Journal of cardiovascular magnetic resonance : official journal of the Society for Cardiovascular Magnetic Resonance 2012, 14(1):83.

20. Zhou G, Soufan O, Ewald J, Hancock REW, Basu N, Xia J: NetworkAnalyst 3.0: a visual analytics platform for comprehensive gene expression profiling and meta-analysis. Nucleic acids research 2019, 47(W1):W234-w241.

21. Li T, Fan J, Wang B, Traugh N, Chen Q, Liu JS, Li B, Liu XS: TIMER: A Web Server for Comprehensive Analysis of TumorInfiltrating Immune Cells. Cancer research 2017, 77(21):e108-e110.

22. Chandrashekar DS, Bashel B, Balasubramanya SAH, Creighton CJ, Ponce-Rodriguez I, Chakravarthi B, Varambally S: UALCAN: A Portal for Facilitating Tumor Subgroup Gene Expression and Survival Analyses. Neoplasia 2017, 19(8):649658.

23. Goswami CP, Nakshatri H: PROGgeneV2: enhancements on the existing database. BMC Cancer 2014, 14:970.

24. Franz M, Rodriguez H, Lopes C, Zuberi K, Montojo J, Bader GD, Morris Q: GeneMANIA update 2018. Nucleic acids research 2018, 46(W1):W60-w64.

25. Boon K, Osorio EC, Greenhut SF, Schaefer CF, Shoemaker J, Polyak K, Morin PJ, Buetow KH, Strausberg RL, De Souza SJ et al: An anatomy of normal and malignant gene expression. Proc Natl Acad Sci U S A 2002, 99(17):11287-11292.

26. Vasaikar SV, Straub P, Wang J, Zhang B: LinkedOmics: analyzing multi-omics data within and across 32 cancer types. Nucleic acids research 2018, 46(D1):D956-d963.

27. Nacev BA, Jones KB, Intlekofer AM, Yu JSE, Allis CD, Tap WD, Ladanyi M, Nielsen TO: The epigenomics of sarcoma. Nature reviews Cancer 2020, 20(10):608-623.

28. Mills JR, Malina A, Lee T, Di Paola D, Larsson O, Miething C, Grosse F, Tang H, Zannis-Hadjopoulos M, Lowe SW et al: RNAi screening uncovers Dhx9 as a modifier of ABT-737 resistance in an Ej-myc/Bcl-2 mouse model. Blood 2013, 121(17):3402-3412.

29. Erkizan HV, Kong Y, Merchant M, Schlottmann S, Barber-Rotenberg JS, Yuan L, Abaan OD, Chou TH, Dakshanamurthy S, Brown ML et al: A small molecule blocking oncogenic protein EWS-FLI1 interaction with RNA helicase A inhibits growth 
of Ewing's sarcoma. Nature medicine 2009, 15(7):750-756.

30. Kamura S, Matsumoto Y, Fukushi JI, Fujiwara T, lida K, Okada Y, Iwamoto Y: Basic fibroblast growth factor in the bone microenvironment enhances cell motility and invasion of Ewing's sarcoma family of tumours by activating the FGFR1PI3K-Rac1 pathway. British journal of cancer 2010, 103(3):370-381.

31. Fridman R, Fuks Z, Ovadia H, Vlodavsky I: Differential structural requirements for the induction of cell attachment, proliferation and differentiation by the extracellular matrix. Exp Cell Res 1985, 157(1):181-194.

32. Manara MC, Terracciano M, Mancarella C, Sciandra M, Guerzoni C, Pasello M, Grilli A, Zini N, Picci P, Colombo MP et al: CD99 triggering induces methuosis of Ewing sarcoma cells through IGF-1R/RAS/Rac1 signaling. Oncotarget 2016, 7(48):79925-79942.

33. Heisey DAR, Lochmann TL, Floros KV, Coon CM, Powell KM, Jacob S, Calbert ML, Ghotra MS, Stein GT, Maves YK et al: The Ewing Family of Tumors Relies on BCL-2 and BCL-X(L) to Escape PARP Inhibitor Toxicity. Clinical cancer research : an official journal of the American Association for Cancer Research 2019, 25(5):1664-1675.

34. Handl M, Hermanova M, Hotarkova S, Jarkovsky J, Mudry P, Shatokhina T, Vesela M, Sterba J, Zambo I:

Clinicopathological correlation of tumor-associated macrophages in Ewing sarcoma. Biomedical papers of the Medical Faculty of the University Palacky, Olomouc, Czechoslovakia 2018, 162(1):54-60.

35. Teicher BA: Searching for molecular targets in sarcoma. Biochemical pharmacology 2012, 84(1):1-10.

36. Nordberg J, Mpindi JP, Iljin K, Pulliainen AT, Kallajoki M, Kallioniemi O, Elenius K, Elenius V: Systemic analysis of gene expression profiles identifies ErbB3 as a potential drug target in pediatric alveolar rhabdomyosarcoma. PLoS One 2012, 7(12):e50819.

37. Behr CA, Hesketh AJ, Barlow M, Glick RD, Symons M, Steinberg BM, Soffer SZ: Celecoxib inhibits Ewing sarcoma cell migration via actin modulation. The Journal of surgical research 2015, 198(2):424-433.

38. Barlow M, Edelman M, Glick RD, Steinberg BM, Soffer SZ: Celecoxib inhibits invasion and metastasis via a cyclooxygenase 2-independent mechanism in an in vitro model of Ewing sarcoma. Journal of pediatric surgery 2012, 47(6):1223-1227.

39. Rose PP, Bogyo M, Moses AV, Früh K: Insulin-like growth factor II receptor-mediated intracellular retention of cathepsin B is essential for transformation of endothelial cells by Kaposi's sarcoma-associated herpesvirus. Journal of virology 2007, 81(15):8050-8062.

40. McAllister SC, Hansen SG, Ruhl RA, Raggo CM, DeFilippis VR, Greenspan D, Früh K, Moses AV: Kaposi sarcomaassociated herpesvirus (KSHV) induces heme oxygenase-1 expression and activity in KSHV-infected endothelial cells. Blood 2004, 103(9):3465-3473.

41. Ma Y, Aymeric L, Locher C, Mattarollo SR, Delahaye NF, Pereira P, Boucontet L, Apetoh L, Ghiringhelli F, Casares N et al: Contribution of IL-17-producing gamma delta T cells to the efficacy of anticancer chemotherapy. The Journal of experimental medicine 2011, 208(3):491-503.

42. Ding I, Liu W, Sun J, Fenton B, Okunieff P: Comparison and modulation of angiogenic responses by FGFs, VEGF and SCF in murine and human fibrosarcomas. Comparative biochemistry and physiology Part A, Molecular \& integrative physiology 2002, 132(1):17-25.

43. Jang $\mathrm{JH}$, Chung CP: Loss of ligand-binding specificity of fibroblast growth factor receptor 2 by RNA splicing in human chondrosarcoma cells. Cancer letters 2003, 191(2):215-222.

44. Ishii H, Hattori Y, Itoh H, Kishi T, Yoshida T, Sakamoto H, Oh H, Yoshida S, Sugimura T, Terada M: Preferential expression of the third immunoglobulin-like domain of K-sam product provides keratinocyte growth factor-dependent growth in carcinoma cell lines. Cancer research 1994, 54(2):518-522.

\section{Tables}

Table 1 The top 5 enriched GO and KEGG terms of the DEGs 


\begin{tabular}{|c|c|c|c|c|c|}
\hline Category & ID & Term & Count & FDR & $P$ value \\
\hline Biological Process & 2000147 & positive regulation of cell motility & 18 & $2.56 \mathrm{E}-04$ & 3.01E-07 \\
\hline Biological Process & 0050900 & leukocyte migration & 16 & $3.42 \mathrm{E}-04$ & 8.06E-07 \\
\hline Biological Process & 0002446 & neutrophil mediated immunity & 16 & 0.001668 & 7.10E-06 \\
\hline Biological Process & 0036230 & granulocyte activation & 16 & 0.001668 & 7.85E-06 \\
\hline Biological Process & 0001667 & ameboidal-type cell migration & 13 & 0.00517 & 3.04E-05 \\
\hline Cellular Component & 0031012 & extracellular matrix & 16 & 0.007648 & 4.45E-05 \\
\hline Cellular Component & 0030667 & secretory granule membrane & 11 & 0.013752 & 2.10E-04 \\
\hline Cellular Component & 0042581 & specific granule & 8 & 0.013752 & 2.40E-04 \\
\hline Cellular Component & 0031091 & platelet alpha granule & 6 & 0.014724 & $3.42 \mathrm{E}-04$ \\
\hline Cellular Component & 0031983 & vesicle lumen & 11 & 0.021102 & $6.88 \mathrm{E}-04$ \\
\hline Molecular Function & 0019838 & growth factor binding & 9 & 0.001155 & 4.10E-06 \\
\hline Molecular Function & 0005201 & extracellular matrix structural constituent & 9 & 0.00174 & $1.23 \mathrm{E}-05$ \\
\hline Molecular Function & 0019199 & transmembrane receptor protein kinase activity & 5 & 0.075694 & 8.05E-04 \\
\hline Molecular Function & 0070851 & growth factor receptor binding & 6 & 0.085822 & 0.001217 \\
\hline Molecular Function & 0001968 & fibronectin binding & 3 & 0.089668 & 0.00159 \\
\hline KEGG pathway & hsa04015 & Rap1 signaling pathway & 10 & 0.022722 & 6.97E-05 \\
\hline KEGG pathway & hsa04014 & Ras signaling pathway & 9 & 0.094754 & $8.58 \mathrm{E}-04$ \\
\hline KEGG pathway & hsa00260 & Glycine, serine and threonine metabolism & 4 & 0.094754 & $8.72 \mathrm{E}-04$ \\
\hline KEGG pathway & hsa05200 & Pathways in cancer & 14 & 0.114305 & 0.001403 \\
\hline KEGG pathway & hsa04142 & Lysosome & 6 & 0.135229 & 0.002093 \\
\hline
\end{tabular}

Table 2 The topological properties of the hub genes 


\begin{tabular}{|lllllll|}
\hline Name & $\begin{array}{l}\text { Average Shortest Path } \\
\text { Length }\end{array}$ & $\begin{array}{l}\text { Betweenness } \\
\text { Centrality }\end{array}$ & $\begin{array}{l}\text { Closeness } \\
\text { Centrality }\end{array}$ & $\begin{array}{l}\text { Clustering } \\
\text { Coefficient }\end{array}$ & $\begin{array}{l}\text { Stress } \\
\text { Topological } \\
\text { Coefficient }\end{array}$ \\
\hline PCL2L1 & 1.444444 & 0.29537 & 0.692308 & 0.2 & 40 & 0.4 \\
\hline CD68 & 1.666667 & 0.291204 & 0.692308 & 0.3 & 36 & 0.425 \\
\hline VEGFC & 1.888889 & 0.143519 & 0.6 & 0.3 & 18 & 0.457143 \\
\hline TEK & 1.888889 & 0.130556 & 0.529412 & 0.333333 & 14 & 0.5 \\
\hline HMOX1 & 1.777778 & 0.12963 & 0.529412 & 0.333333 & 14 & 0.5 \\
\hline CTSD & 1.888889 & 0.0125 & 0.5625 & 0.666667 & 4 & 0.625 \\
\hline CTSB & 1.888889 & 0.0125 & 0.529412 & 0.666667 & 4 & 0.619048 \\
\hline FGF7 & 2.333333 & 0.0125 & 0.529412 & 0.666667 & 4 & 0.619048 \\
\hline IL1R1 & 2 & 0 & 0.428571 & 1 & 0 & 0.75 \\
\hline
\end{tabular}

Table 3 The top 5 miRNAs that regulated the DEGs and hub genes with their topological properties 


\begin{tabular}{|c|c|c|c|c|c|c|c|c|}
\hline Name & $\begin{array}{l}\text { Average } \\
\text { Shortest } \\
\text { Path } \\
\text { Length }\end{array}$ & $\begin{array}{l}\text { Betweenness } \\
\text { Centrality }\end{array}$ & $\begin{array}{l}\text { Closeness } \\
\text { Centrality }\end{array}$ & Degree & $\begin{array}{l}\text { Neighborhood } \\
\text { Connectivity }\end{array}$ & Radiality & Stress & $\begin{array}{l}\text { Topological } \\
\text { Coefficient }\end{array}$ \\
\hline \multicolumn{9}{|c|}{ Top 5 miRNAs that regulated the DEGs } \\
\hline $\begin{array}{l}\text { hsa- } \\
\text { mir- } \\
124- \\
3 p\end{array}$ & 3.07 & 0.05 & 0.33 & 30.00 & 34.10 & 0.99 & 7660044.00 & 0.05 \\
\hline $\begin{array}{l}\text { hsa- } \\
\text { mir- } \\
335- \\
5 p\end{array}$ & 3.31 & 0.03 & 0.30 & 26.00 & 25.46 & 0.99 & 4730544.00 & 0.05 \\
\hline $\begin{array}{l}\text { hsa- } \\
\text { mir- } \\
16-5 p\end{array}$ & 3.11 & 0.04 & 0.32 & 24.00 & 42.13 & 0.99 & 5834724.00 & 0.06 \\
\hline $\begin{array}{l}\text { hsa- } \\
\text { mir- } \\
26 b- \\
5 p\end{array}$ & 3.37 & 0.02 & 0.30 & 21.00 & 29.38 & 0.99 & 3155496.00 & 0.06 \\
\hline $\begin{array}{l}\text { hsa- } \\
\text { mir-1- } \\
\text { 3p }\end{array}$ & 3.14 & 0.02 & 0.32 & 18.00 & 48.56 & 0.99 & 3552162.00 & 0.07 \\
\hline \multicolumn{9}{|c|}{ Top 5 miRNAs that regulated the hub genes } \\
\hline $\begin{array}{l}\text { hsa- } \\
\text { mir- } \\
218- \\
5 p\end{array}$ & 2.15 & 0.17 & 0.47 & 4.00 & 64.25 & 0.99 & 72418.00 & 0.26 \\
\hline $\begin{array}{l}\text { hsa- } \\
\text { mir- } \\
122- \\
5 p\end{array}$ & 2.31 & 0.10 & 0.43 & 3.00 & 77.00 & 0.99 & 55576.00 & 0.35 \\
\hline $\begin{array}{l}\text { hsa- } \\
\text { mir- } \\
\text { 335- } \\
5 p\end{array}$ & 3.47 & 0.02 & 0.29 & 3.00 & 24.33 & 0.98 & 47136.00 & 0.36 \\
\hline $\begin{array}{l}\text { hsa- } \\
\text { mir- } \\
128- \\
3 p\end{array}$ & 3.30 & 0.04 & 0.30 & 3.00 & 32.33 & 0.99 & 56582.00 & 0.36 \\
\hline $\begin{array}{l}\text { hsa- } \\
\text { mir- } \\
124- \\
3 p\end{array}$ & 3.46 & 0.05 & 0.29 & 3.00 & 24.00 & 0.98 & 56932.00 & 0.35 \\
\hline
\end{tabular}

Table 4 The top 5 TFs that regulated the DEGs and hub genes with topological properties 


\begin{tabular}{|lllllllll|}
\hline Name & $\begin{array}{l}\text { Average } \\
\text { Shortest } \\
\text { Path } \\
\text { Length }\end{array}$ & $\begin{array}{l}\text { Betweenness } \\
\text { Centrality }\end{array}$ & $\begin{array}{l}\text { Closeness } \\
\text { Centrality }\end{array}$ & Degree & $\begin{array}{l}\text { Neighborhood } \\
\text { Connectivity }\end{array}$ & Radiality & Stress & $\begin{array}{l}\text { Topological } \\
\text { Coefficient }\end{array}$ \\
\hline Top 5 TFs that regulated the DEGs & & & & & & & \\
\hline TFDP1 & 2.25 & 0.01 & 0.44 & 32.00 & 48.09 & 0.99 & 347300.00 & 0.17 \\
\hline ZNF580 & 2.25 & 0.01 & 0.44 & 30.00 & 46.80 & 0.99 & 271646.00 & 0.16 \\
\hline ZBTB11 & 2.32 & 0.01 & 0.43 & 30.00 & 43.87 & 0.99 & 248966.00 & 0.16 \\
\hline PHF8 & 2.31 & 0.01 & 0.43 & 29.00 & 32.86 & 0.99 & 191210.00 & 0.12 \\
\hline KDM5B & 2.31 & 0.01 & 0.43 & 29.00 & 32.86 & 0.99 & 191210.00 & 0.12 \\
\hline Top 5 TFs that regulated the hub genes & & & & & 0.99 & 32672.00 & 0.34 \\
\hline ZNF580 & 2.01 & 0.02 & 0.50 & 5.00 & 68.60 & 0.99 & 0.32 \\
\hline MXD3 & 2.34 & 0.01 & 0.43 & 5.00 & 53.00 & 0.99 & 18220.00 & 0.30 \\
\hline SAP30 & 2.55 & 0.01 & 0.39 & 4.00 & 44.25 & 0.99 & 18254.00 & 0.93 \\
\hline KDM5B & 2.55 & 0.01 & 0.39 & 4.00 & 44.25 & 0.99 & 18254.00 & 0.30 \\
\hline PHF8 & 2.55 & 0.01 & 0.39 & 4.00 & 44.25 & 0.99 & 18254.00 & 0.30 \\
\hline
\end{tabular}

Figures 
A

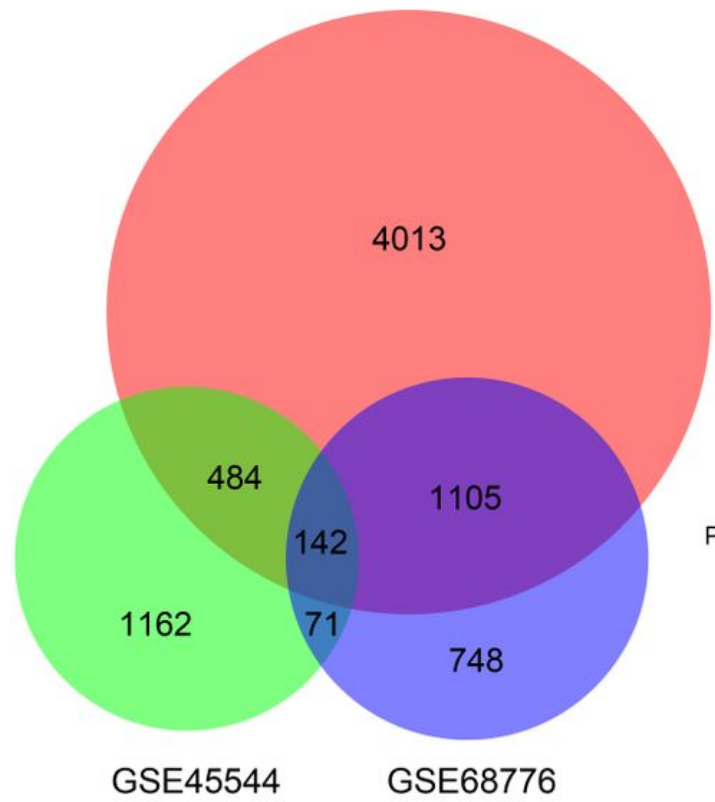

C

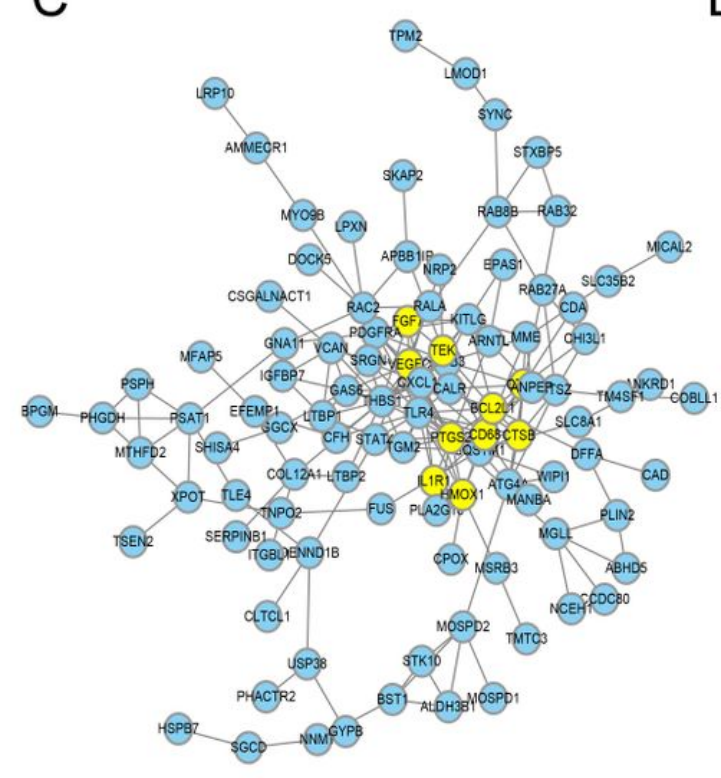

B

- Muscle Skeletal

- SARC Normal

- SARC Tumor

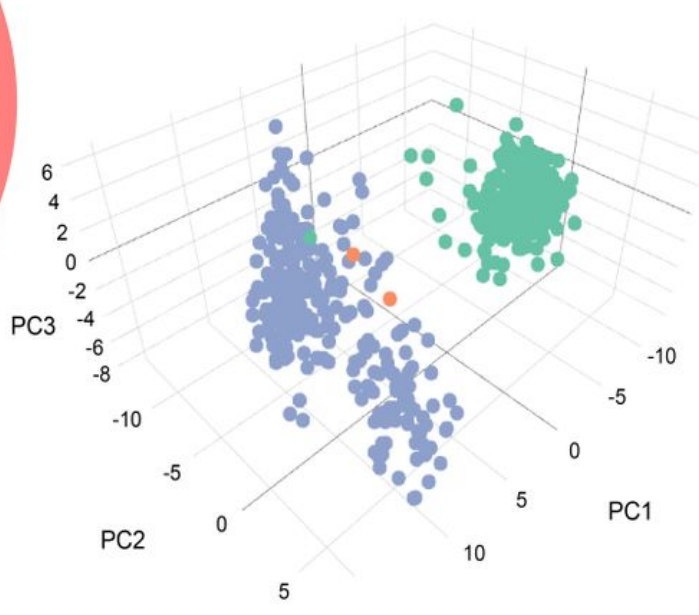

D

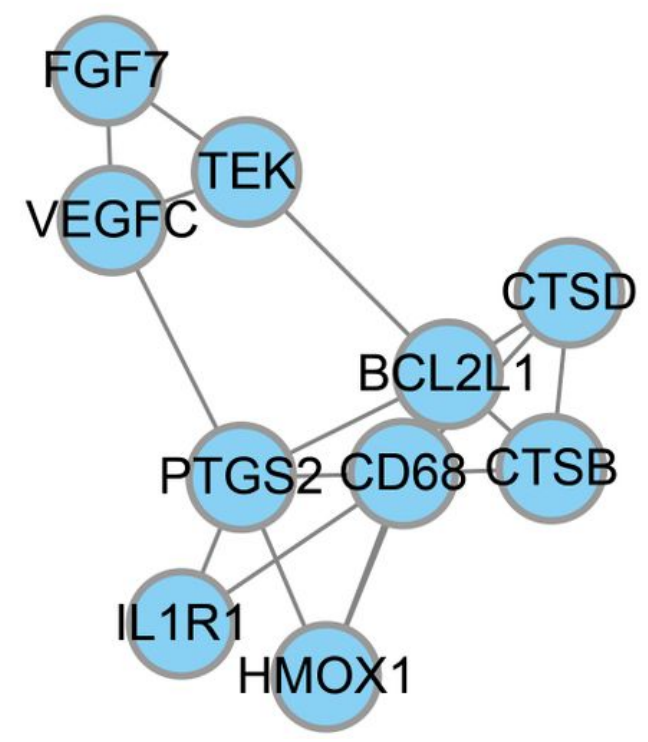

Figure 1

Venn diagram, 3D-PCA, PPI network, and the most significant module of the DEGs. The DEGs were selected with a fold change $>2$ and P-value $<0.01$ among the mRNA expression profiling sets GSE45544, GSE68591, and GSE68776. The 3 datasets showed an overlap of 142 genes (A). The 3D-PCA dimensionality reduction was performed on samples from tumor sarcoma tissue, normal tissue, and skeletal muscle tissue (B). The PPI network of the DEGs was constructed and visualized by Cytoscape; the blue nodes represent DEGs, the yellow nodes represent the most significant module obtained from the PPI network (C). The details of the most significant module (D). 
A

\section{Biological Process}

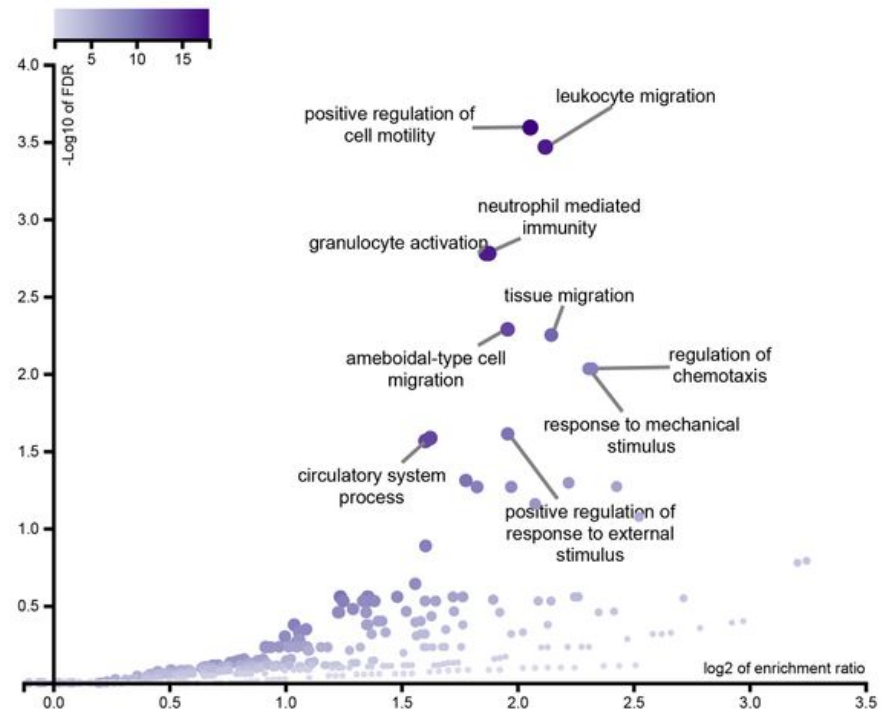

C

\section{Molecular Function}

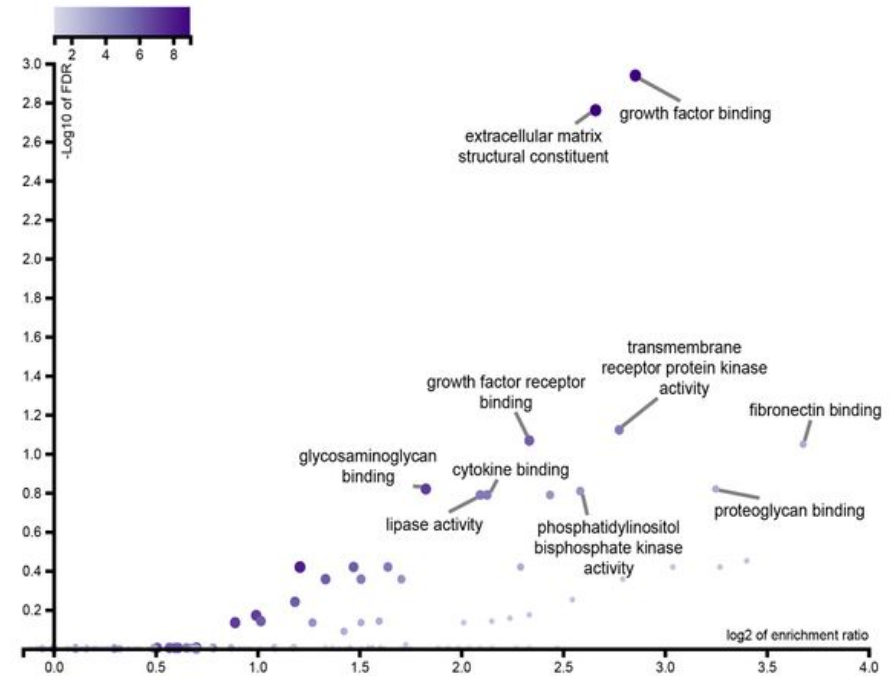

B

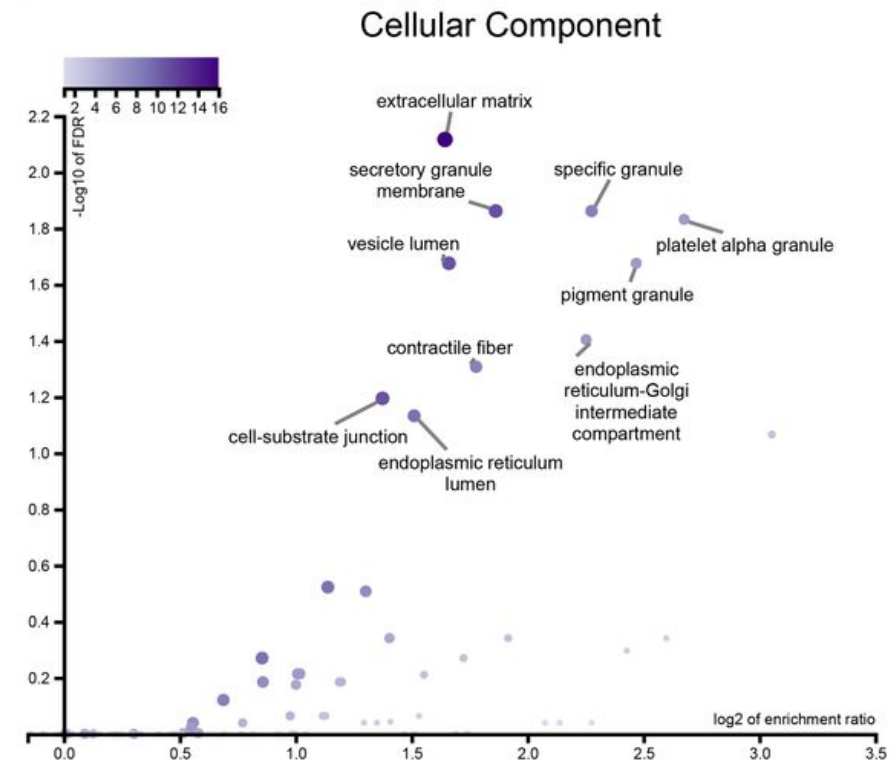

D

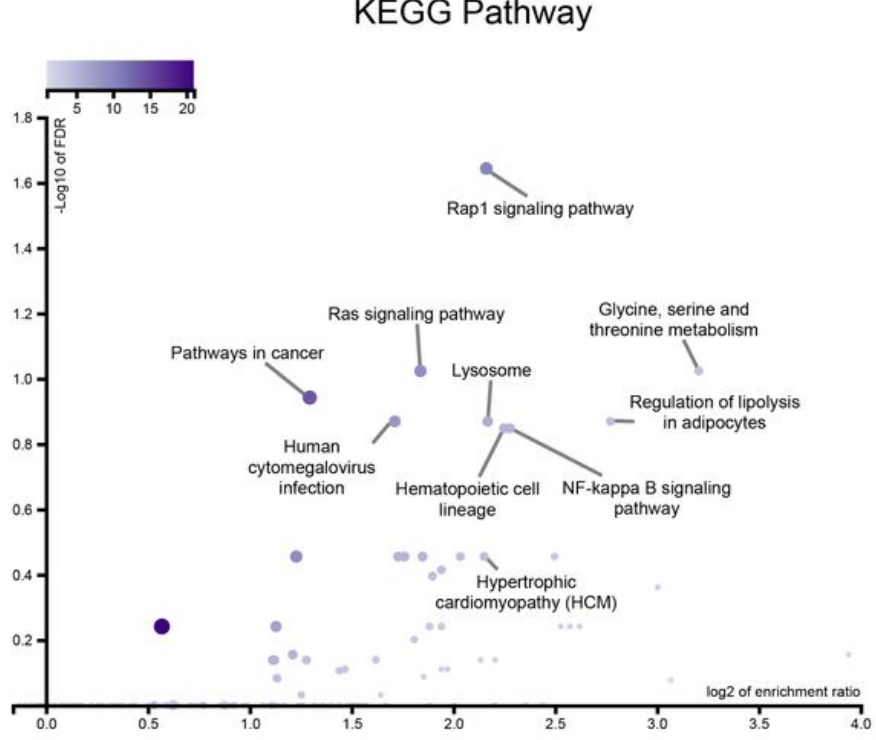

Figure 2

GO and pathway enrichment analyses of the DEGs. These include the biological process (A), cellular component (B), molecular function (C), and KEGG pathway(D). 
A

\section{DEG-miRNA}

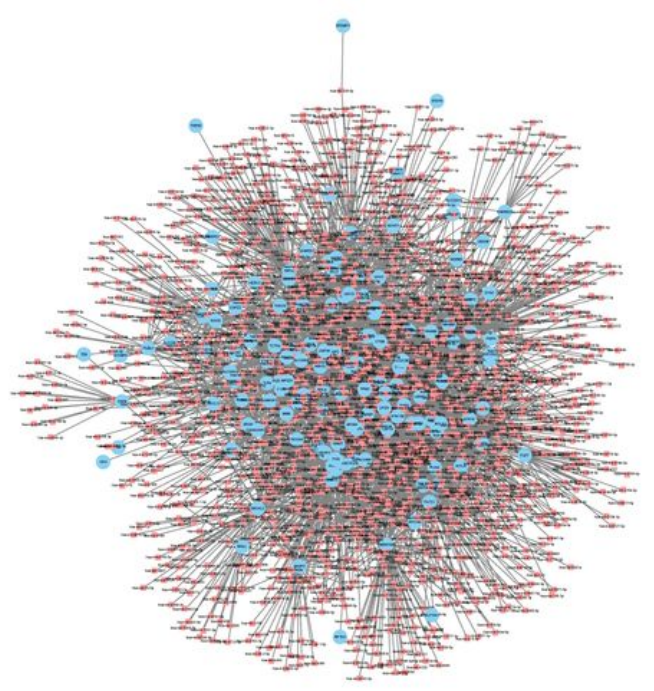

C Hub gene-miRNA

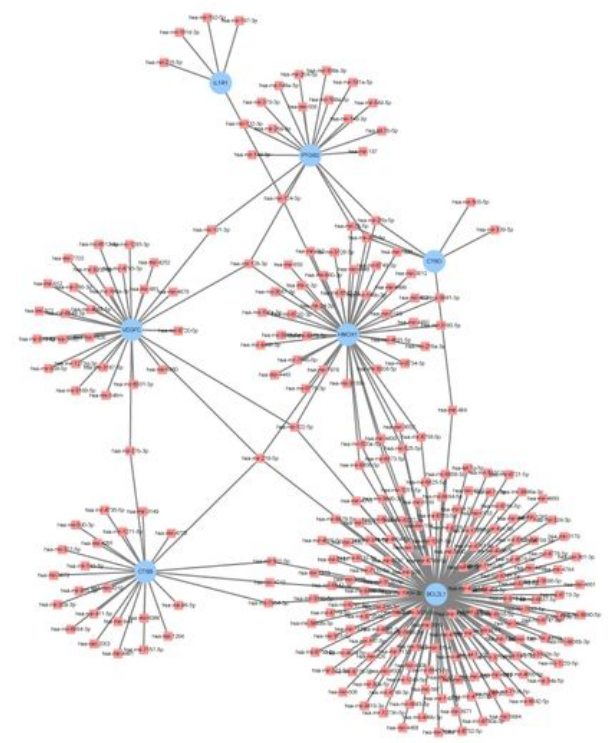

B

\section{TF-DEG}

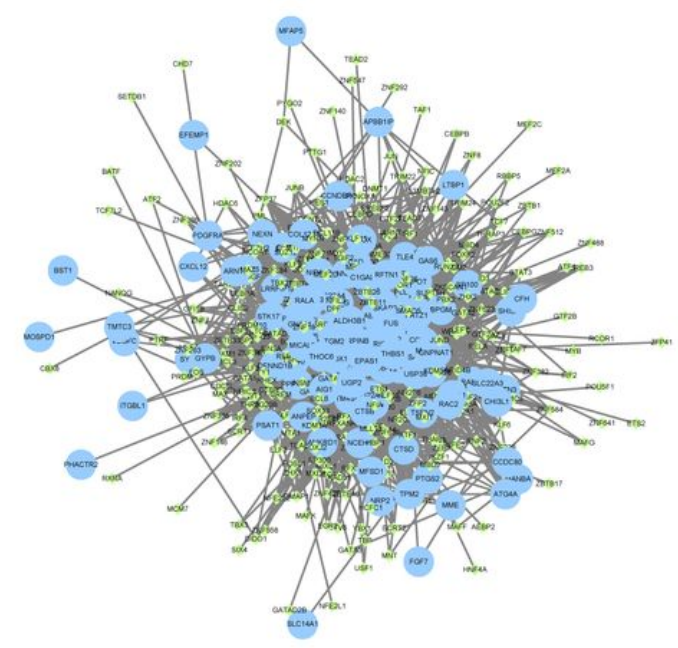

D

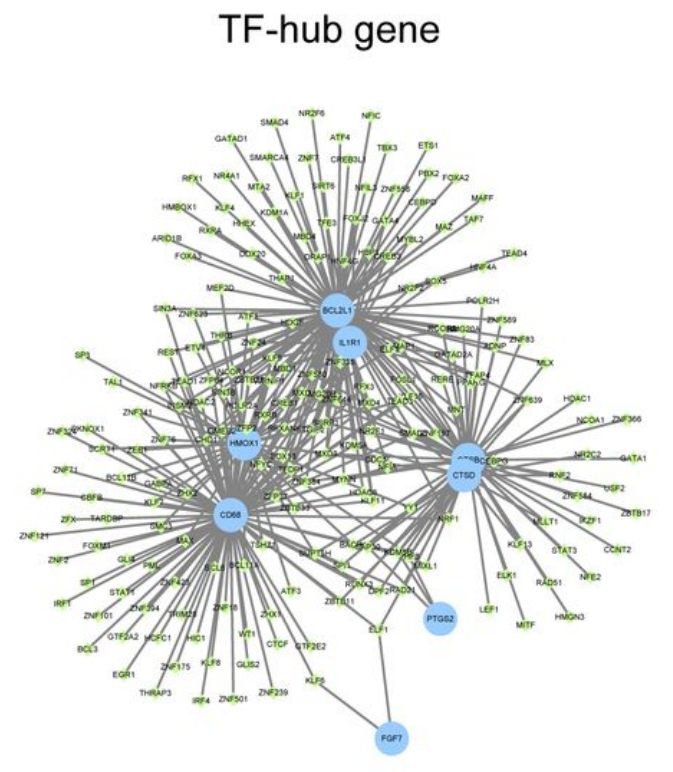

\section{Figure 3}

Regulatory network of DEGs and hub genes, such as DEG-miRNA (A), TF-DEG(B), the hub gene-miRNA(C), and TF-the hub gene (D). The blue nodes represent genes, the red nodes represent miRNAs, and the blue nodes represent TFs. 

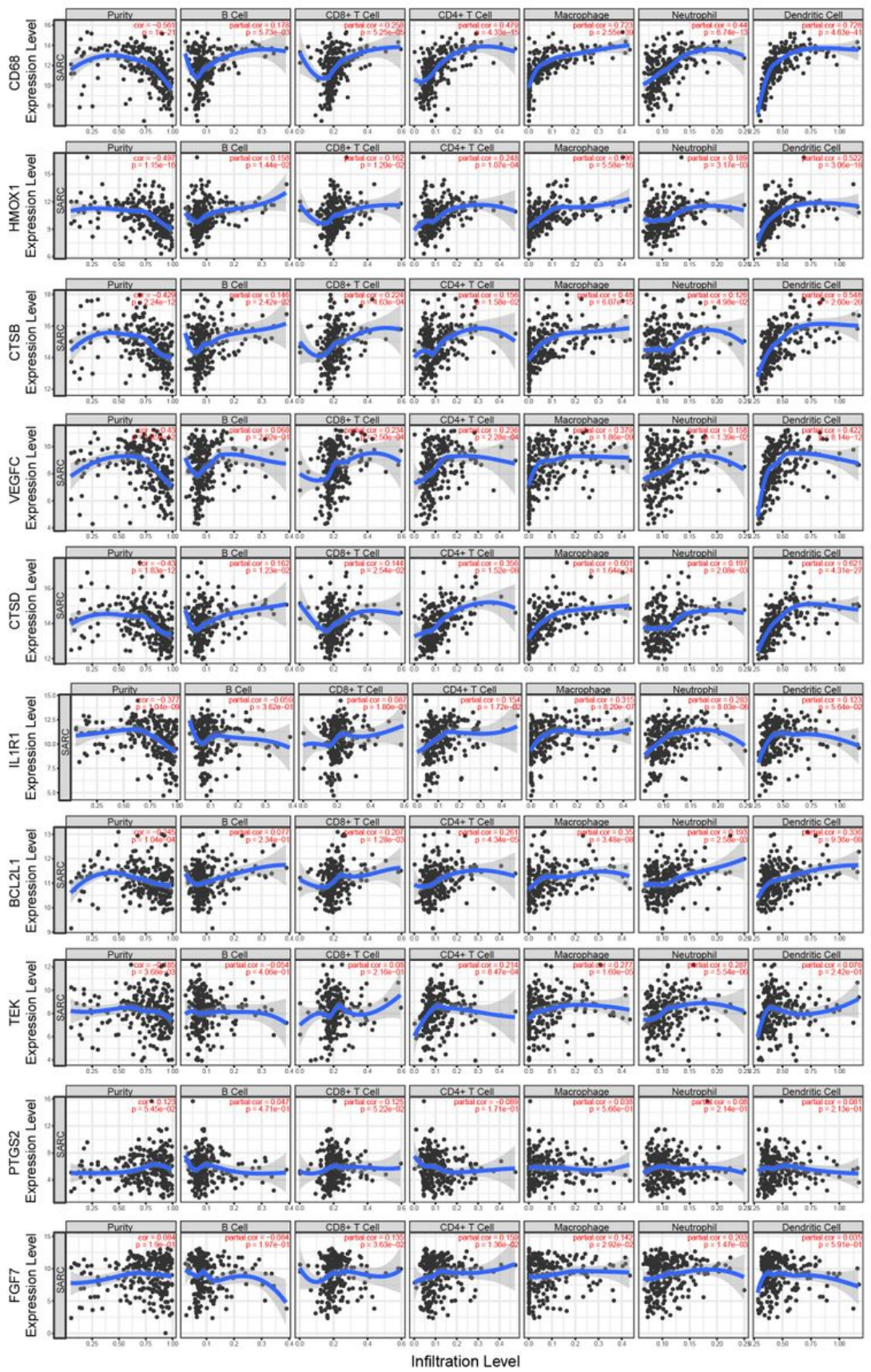

Figure 4

Immune infiltration of hub genes. The expression level of hub genes was correlated with the purity of the sarcoma tumor and the level of immune cell infiltration. 
A

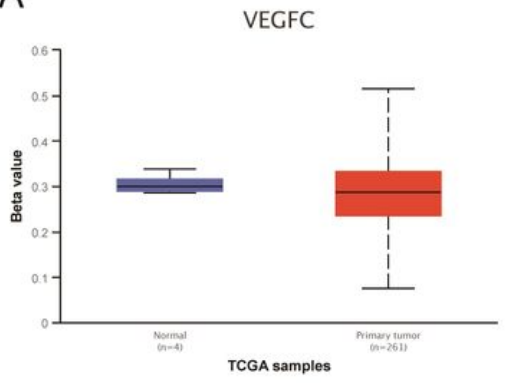

D

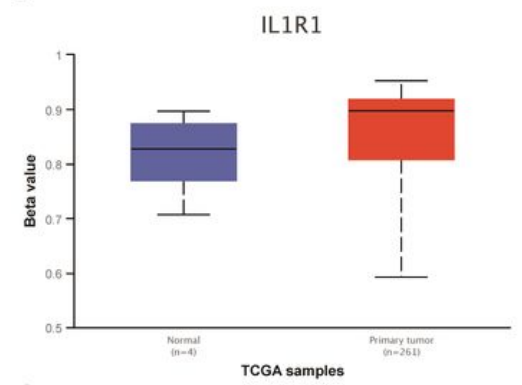

G

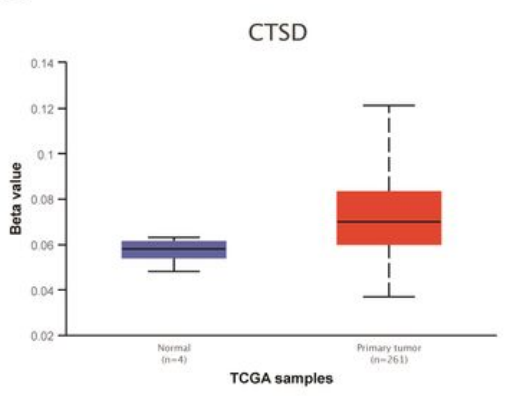

J

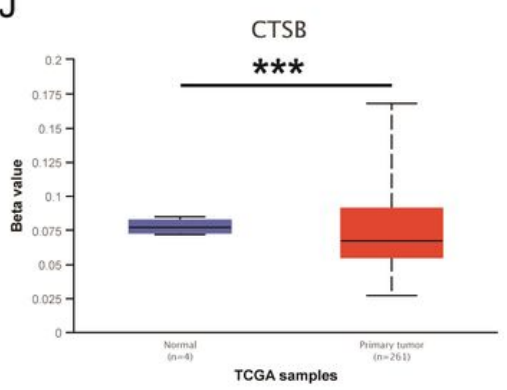

B

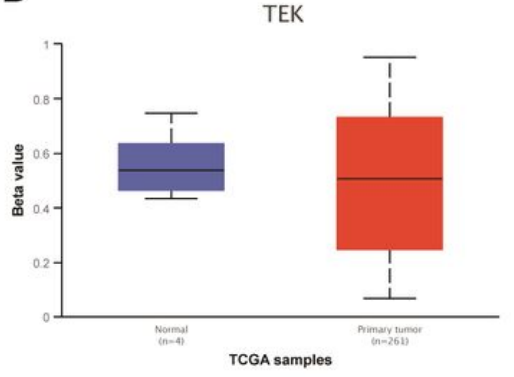

E

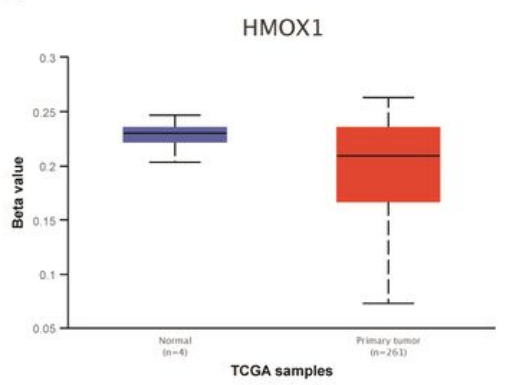

$\mathrm{H}$

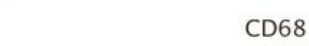

C

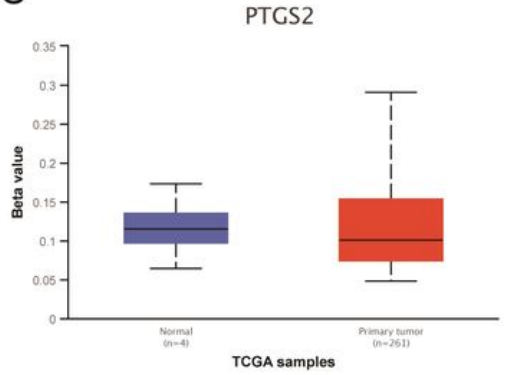

F

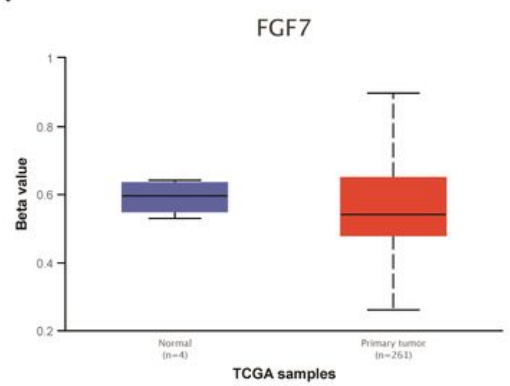

I

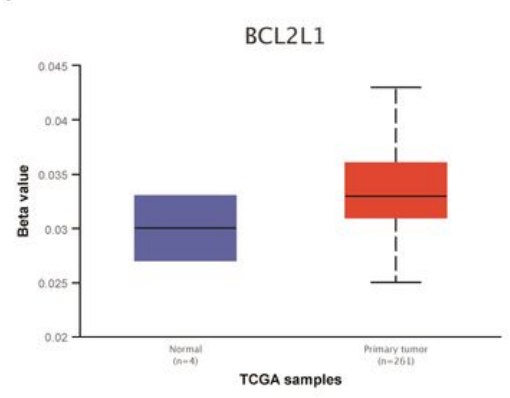

Figure 5

The methylation levels in promoter regions of hub genes. Comparison of DNA methylation levels in the promoter region of hub genes (A-J) between SARC and normal tissues. $\left({ }^{\star * \star} p<0.001\right)$ 
A

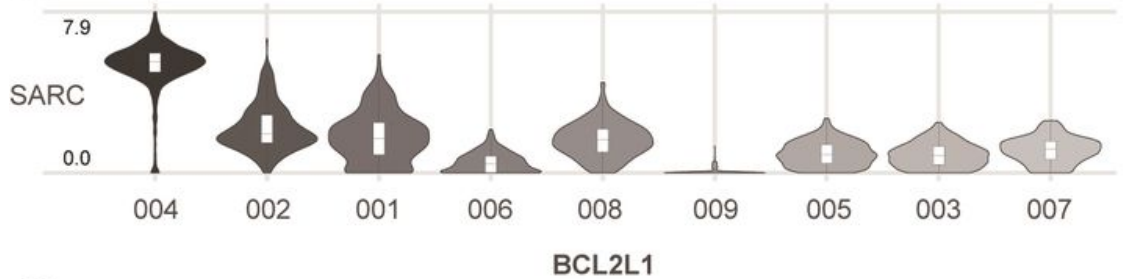

B

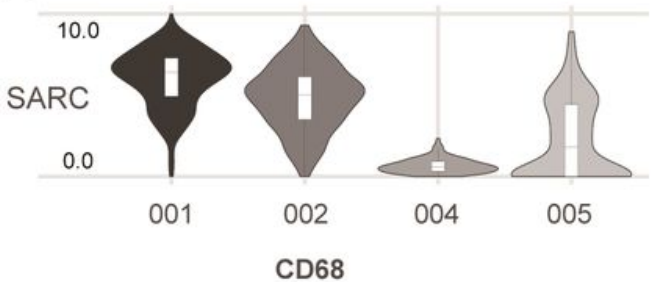

C

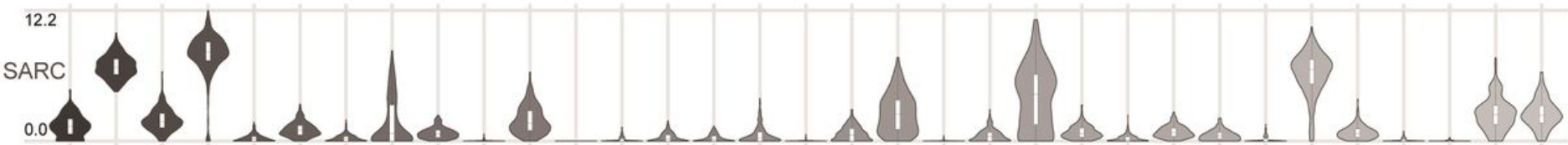
007001041006033016025026034020042027014021032038019039003004013011035024036030037002017018023005015

D

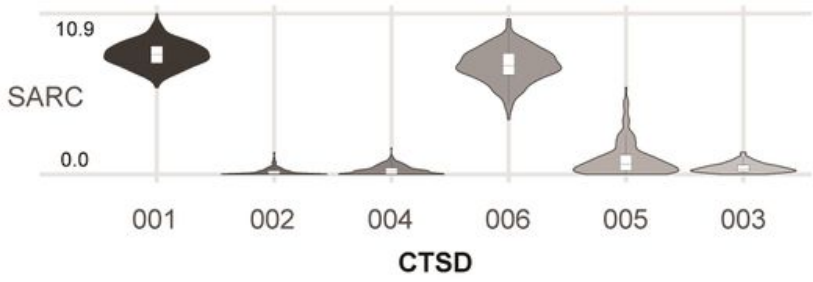

$\mathrm{F}$

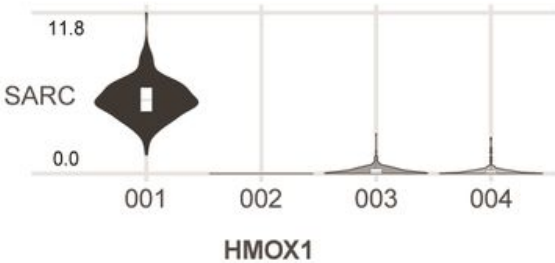

I

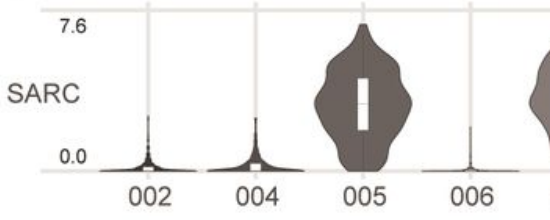

G

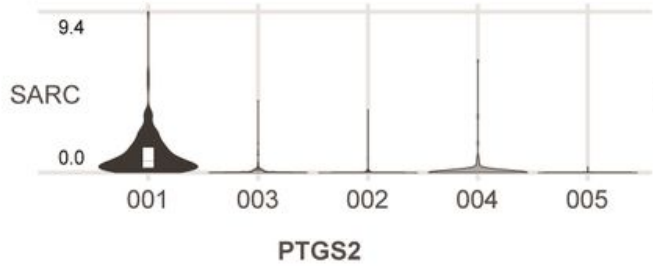

PTGS2
E

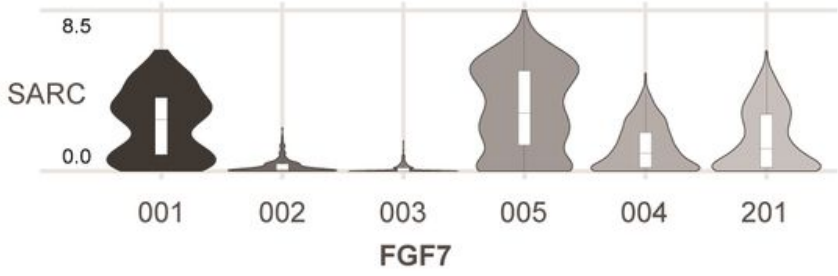

$\mathrm{H}$

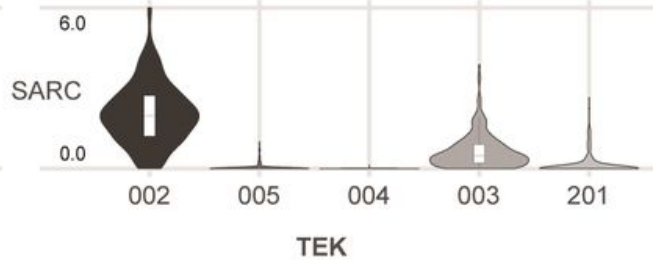

$\mathrm{J}$

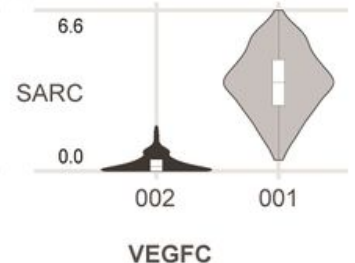

Figure 6

Expression of hub genes isoforms in SARC samples. Comparison of the expression levels of hub genes isoforms (A-J) in SARC. 
A

B $\quad$ C

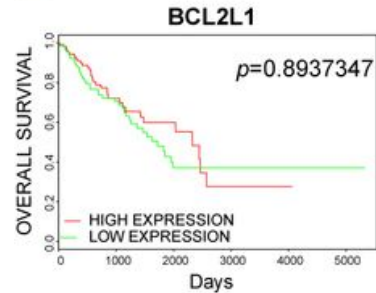

CD68
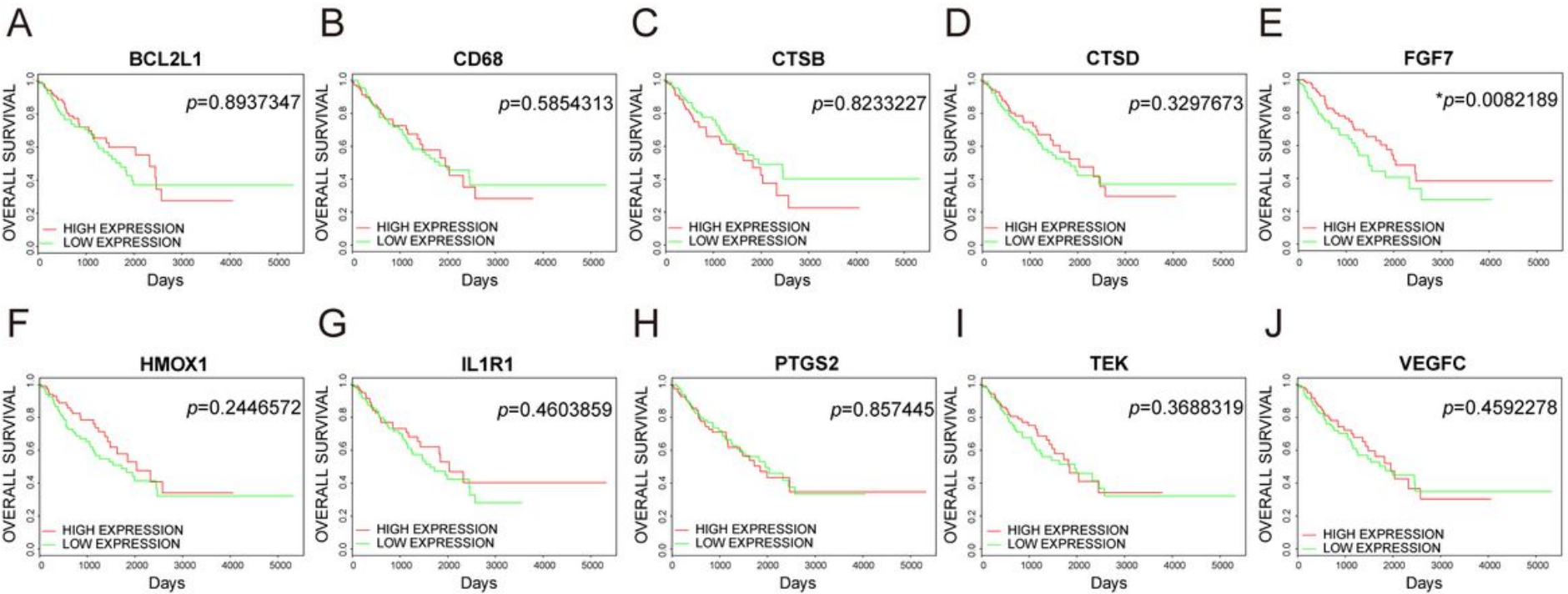

\section{Figure 7}

Survival analysis of hub genes. The relationship between the expression level of hub genes (A-J) and the overall survival rate of patients with osteosarcoma. The red line represents a high expression of the genes, and the green line represents a low expression of the genes. 
A

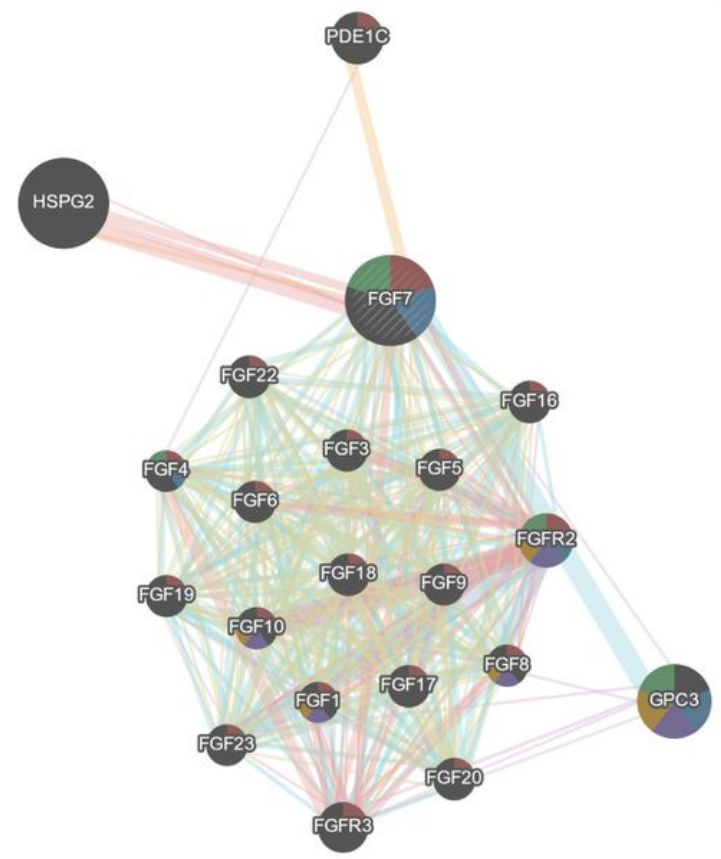

Networks

III Physical Interactions

= Co-expression

II Predicted

- Co-localization

I- Pathway

- Genetic Interactions

II Shared protein domains

C

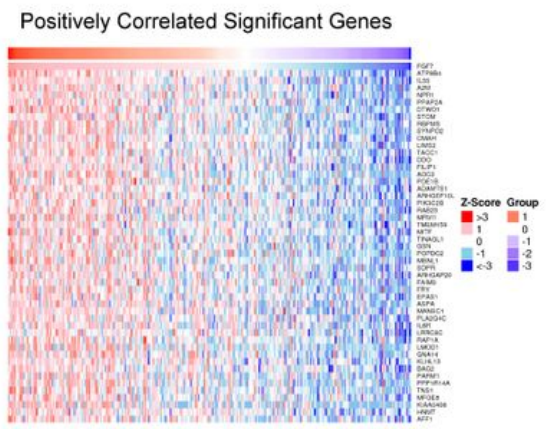

Functions

fibroblast growth factor receptor

signaling pathway

- mesenchymal cell proliferation

n renal system development

= urogenital system development

n stem cell proliferation

\section{D}

B

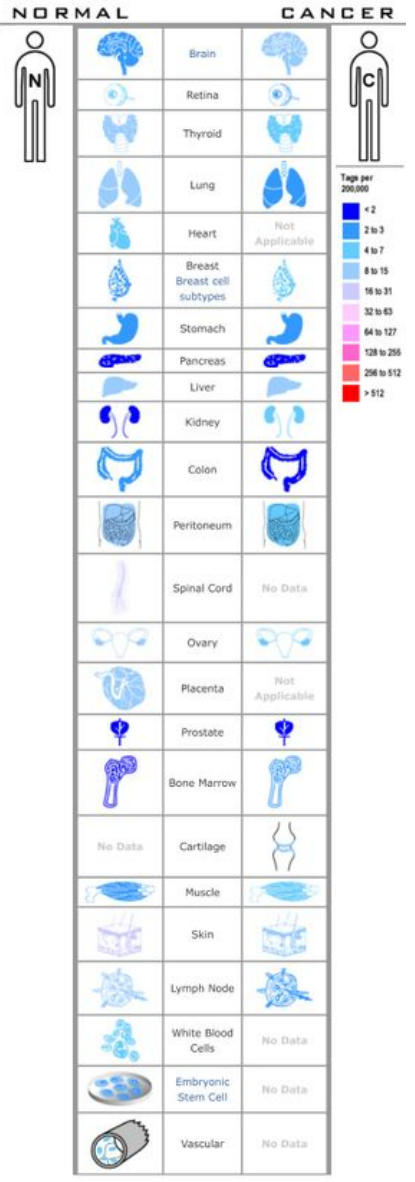

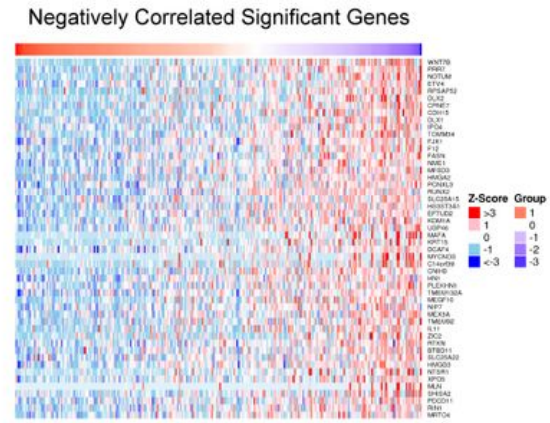

Figure 8

The prediction of functions of the candidate gene FGF7. In the functional association network (A), the edge-colors represent the bioinformatics method applied; the node-colors represent the biological functions of the set of enrichment genes. In the expression profiles (B), the left side represents normal tissues and the right side represents the matched cancer tissues. The related expression levels are based on the analysis of the counts of SAGE tags, ordered by ten colors. The gene expression correlation heatmaps show the most positively correlated significant genes (C) and the most negatively correlated significant genes (D). 